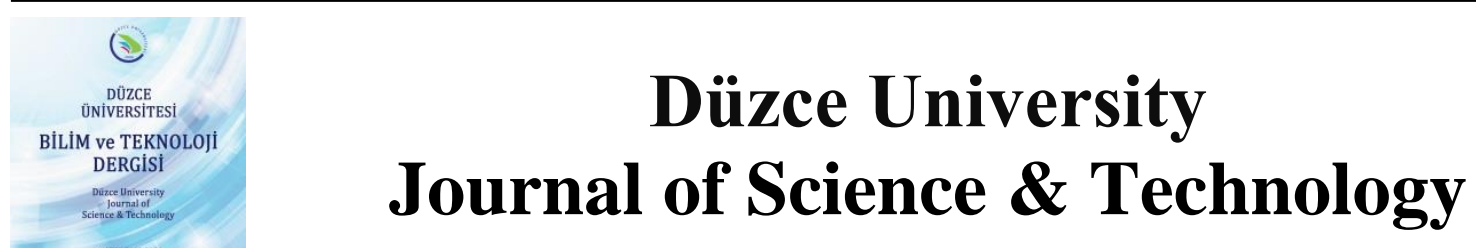

Research Article

\author{
The Luminance Estimation of Basketball Halls Using Machine \\ Learning Methods \\ Mehmet KAYAKUŞ ${ }^{\mathrm{a}, *}$, (D) İsmail Serkan ÜNCÜ \\ ${ }^{a}$ Department of Business Informatics, Faculty of Social Sciences and Humanities, Akdeniz University, \\ Antalya, TURKEY \\ ${ }^{b}$ Department of Electrical-Electronics Engineering, Faculty of Technology, Isparta University of \\ Applied Sciences, Isparta, TURKEY \\ *Corresponding author's e-mail address: mehmetkayakus@akdeniz.edu.tr
}

DOI: $10.29130 /$ dubited.724759

\begin{abstract}
Indoor sports halls are places in which artificial lighting is needed and lighting should be monitored in order to provide a healthy sports environment. It is of utmost importance for maintaining player performances and their health and the visual ability and comfort of the spectator watching matches on TV. Lighting should be maintained and monitored in a planned manner starting from the construction period. It takes a long of period of time to perform measurements using point measuring tools in indoor sports halls. In this study, the luminance estimation of an indoor sports hall was made using machine learning techniques in order to find a solution to this problem. In order to form the data set, 91 reference points were identified according to the standards in the sports hall. The luminance of these points was measured and pixel values of these points (R, G, B) were identified on the photograph taken. 91 reference points were randomly categorized as training data $(70 \%)$ and test data $(30 \%)$. In the study, Probabilistic Neural Network (PNN) and Support Vector Machine (SVM) techniques were used as machine learning methods. The mean square error (MSE), the root mean square error (RMSE), the correlation coefficient and the accuracy rate methods were used in order to test the success rate of these techniques.
\end{abstract}

Keywords: Sports halls 1, lighting 2, machine learning 3, luminance 4

\section{Basketbol Salonlarının Parıltısının Makina Öğrenme Yöntemleriyle Tahmini}

\footnotetext{
ÖZET

Kapalı spor salonları yapay aydınlatmaya ihtiyaç duyulan ve sağlıklı spor yapılabilmesi için aydınlatmanın kontrol altında tutulması gereken alanlardandır. Oyuncu performansları ve sağlıkları korumak için; TV'de maç izleyen seyircilerin görüş yeteneği ve konforu için önemlidir. Aydınlatma yapım aşamasından başlayarak planlı bir şekilde bakımları ve kontrolleri yapılmalıdır. Kapalı spor salonlarında noktasal ölçü aletleriyle yapılan ölçümler uzun zaman almaktadır. Bu çalı̧mada bu soruna çözüm bulmak için makine öğrenme teknikleri kullanılarak kapalı spor salonunun parıltı ölçümleri yapılmıştır. Veri setini oluşturmak için spor salonunda standartlarda olduğu gibi 91 tane referans noktası belirlenmiştir. Belirlenen bu noktaların parıltısı ölçülmüş ve çekilen fotoğrafı üzerinden bu noktaların piksel değerleri (R,G,B) hesaplanmıştır.
} 
91 veri seti rastgele olarak \%70 eğitim verisi, \%30 test verisi olarak ayrılmıştır. Çalışmada makine öğrenme yöntemi olarak Olasılıksal Sinir Ağı (PNN) ve Destek Vektör Makinesi (SVM) teknikleri kullanılmıştır. Tekniklerin başarısını ölçmek için Ortalama Hata Karesi (MSE), Kök Ortalama Kare Hatası (RMSE), korelasyon katsayısı ve doğruluk oranı yöntemleri kullanılmışıtır.

Anahtar Kelimeler: Spor salonları 1, aydınlatma 2, makine ögrenmesi 3, parlltı 4

\section{INTRODUCTION}

The main purpose of lighting design is to meet the needs of end-users during the installation lifetime [1]. The main purpose of sports lighting is to provide an illuminated environment suitable for athletes and the spectator [2]. Good vision could only be achieved with a good lighting system. The quality and amount of lighting in sports halls affects the security of both athletes and the spectators as well as competition. Therefore, player performances increase, and the risk of injury decreases while the spectators could enjoy matches more, broadcast quality increases, and referees make less mistakes. In addition, lighting design and its quality in sports halls will affect the country's image when it hosts international events [3].

Among parameters of lighting design in sports hall are lighting amount, discomfort glare, contrast, and luminous uniform [2]. Sports lighting systems have long service lives because they are used only in the evening and rarely throughout the year [1].

Lighting problems may occur in indoor sports halls. The first one is erroneous lighting projects in the construction period. Defective luminaire installations, using lamps with extra or inadequate power, and defective electrical connection are among these problems. In addition, lighting problems may occur in indoor sports halls over time. An increase in light loss factors, glare, dirty luminaires and luminaire breakdown are some of these problems $[2,4]$.

Lighting measurements should be performed periodically in order to identify lighting problems in indoor sports halls. A wide range of measuring instruments is available for different measuring parameters. This includes illuminance meters (light meters), luminance meters, integrating spheres, goniophotometer systems, colorimeters, spectroradiometers and spectrophotometers [5]. Hardware tools could be used for point measuring lighting conditions. It is difficult to evaluate the entire corridor or a longer section when using traditional manual measurement methods[6].

New lighting measurement methods have been developed over time to overcome these difficulties. Zhou et al. has developed a system consisting of a light meter, a distance meter (DMI), a computer, software, and an electronic converter circuit to connect the computer and other hardware to collect lighting level data[6]. Zimmer, a mobile lighting assessment system has been developed to collect lighting data for high mast lighting systems[7]. Zatari et al. has been developed complex system by which the device (CCD) camera attached to a test vehicle is mounted to to achieve glare, luminance, and illuminance measurements[8].

Today, artificial intelligence techniques are used in different fields of lighting technology (intelligent road lighting, energy efficiency etc.) for different purposes [9-11]. Little documentation has been found that lighting illuminance measurement using artificial intelligence method [12]. Şahin et al. they 
used artificial neural networks[11] to estimate the luminous distribution in the interior and to control the efficiency of lighting systems with different physical properties. They used the feed-forward back propagation ANN model, consisting of 10 input values and an output value (distribution of interior illuminance level). The system successfully made its predictions with $1 \%$ error.[13]. Kazanasmaz et al. developed a prediction model using ANN to determine daylight illumination in office buildings. ANN architecture consists of a three-level model and an output variable. While 80 of the 100 sets of data are used for training, 20 are reserved for the testing phase. The performance of the model was tested using the bright percentage of errors and an accuracy of 98\% was achieved.[14]. Fonseca et al. have developed a model that uses energy-efficient ANN and multiple linear regression methods in office buildings by using daylight. In the model using 216 data, $\mathrm{R}^{2}$ is 0.99 ; correlation is 0.9950 , MSE 0.0303, MAE 0.0221 [15]. In sports halls measurements, only traditional (hardware) methods are used. In the literature, there is no study about illumination measurement using artificial intelligence.

In this study, the luminance of an indoor sports hall was measured by the system developed using machine learning techniques. In the study, Probabilistic Neural Network (PNN) and Support Vector Machine (SVM), two machine learning methods, were used. Success rates of machine learning were compared with values obtained using hardware measurement tools. The accuracy rate, the mean square error (MSE), the correlation efficient, and the root mean square error (RMSE) methods were used in order to identify the accuracy of results, the success rate, and the error rate.

\section{MATERIAL AND METHOD}

When analysed, the literature on photometric measurement demonstrates that measurements are performed using hardware measuring tools. In our previous study, we found that there was a relation between "Silicon Photocell" in the functioning system of luminance meters and camera measurement systems [12]. The luminance meter perceives the amount of light reflected from the surface using silicon photocell sensor. Cameras form images according to the amount of light. Light is a fundamental element in the working principles of both devices.

Lighting design should be for television broadcasting and glare should be minimized for athletes, spectators, and authorities. Lighting in sports halls is composed of two main components called vertical and horizontal lighting. Vertical lighting is an important parameter for the image quality of the main camera and the mobile camera. If the playfield has vertical lighting in different locations and at changing levels, moving the camera could be discomforting. Therefore, uniformity in the distribution of vertical lighting in the playfield is important [16].

In the data collection process, locations on the basketball court in which data would be collected were identified for the artificial intelligence technique used in the present study. Therefore, measurement points identified in the booklet titled Official Basketball Rules [16] of FIBA should be marked in the basketball court as shown in Figure 1. 


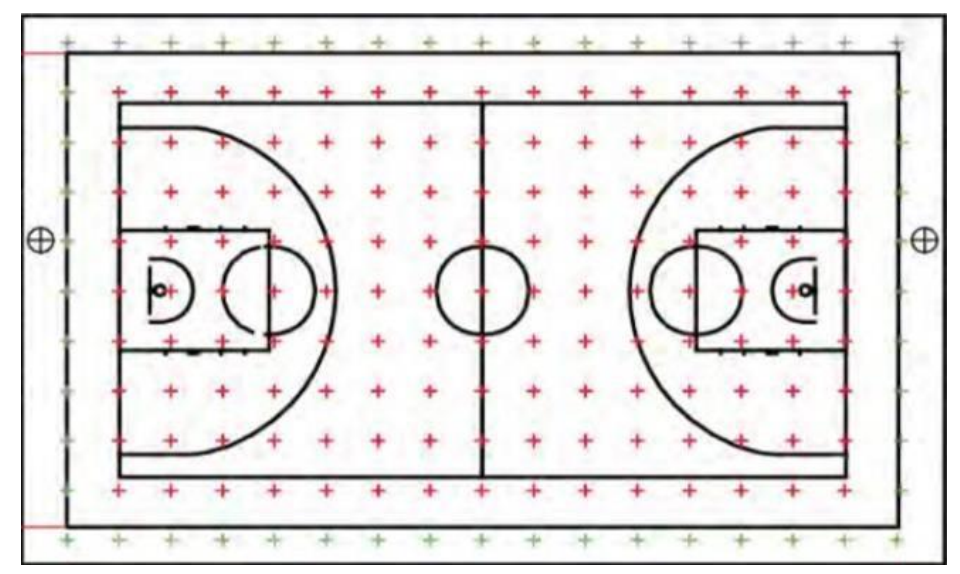

Figure 1. Measurement points [16]

In order to identify the reference points in the playfield shown in Figure 1, the playfield is marked with 2-meter gaps starting from the upper left corner. 91 reference points, 13 horizontally and 7 vertically, are identified. The luminance of these points is measured using luminance meter, and pixel values are measured using an image acquisition system.

PNN and SVM methods, two machine learning methods, were used in order to find a relationship between these two data sets. In order to test the accuracy and error rates of measurements, statistical methods such as MSE, RMSE, correlation efficient [1] and accuracy rate were used.

The mean square error (MSE) is used in order to identify how close a regression curve is to a number of points. The fact that MSE value is close to zero indicates that estimations have a better performance.

MSE $=\frac{1}{n} \sum_{i=1}^{n}\left(y_{i}-x_{i}\right)^{2}$

The root mean square error (RMSE) method is a quadratic metric that is often used in finding the distance between estimated values and real values measuring the error size. The fact that RMSE is equal or close to zero indicates that estimations have a better performance.

$\operatorname{RMSE}=\sqrt{\frac{1}{n} \sum_{i=1}^{n}\left(y_{i}-x_{i}\right)^{2}}$

Equations (1) and (2), i sample number, y measured value, $x$ estimated value.

Correlation shows the linear relationship between two or more variables. The amount of relationship between the two variables is calculated using correlation techniques called binary or simple correlation. The relationship between the variables is calculated by the correlation coefficient. The correlation coefficient between $\mathrm{x}$ and $\mathrm{y}$ values is calculated by the formula in Equation 3 . 


$$
r=\frac{n \sum x y-\left(\sum x\right)\left(\sum y\right)}{\sqrt{n\left(\sum x^{2}\right)-\left(\sum x\right)^{2} \sqrt{n\left(\sum y^{2}\right)-\left(\sum y\right)^{2}}}}
$$

\section{A. WORKING PRINCIPLE OF THE SYSTEM}

The working principle of the system forms a correlation between the luminance value measured on the floor of the sports hall and pixel values $(\mathrm{R}, \mathrm{G}, \mathrm{B})$ on the image of the sports halls. The working principle of the system is shown in Figure 2.

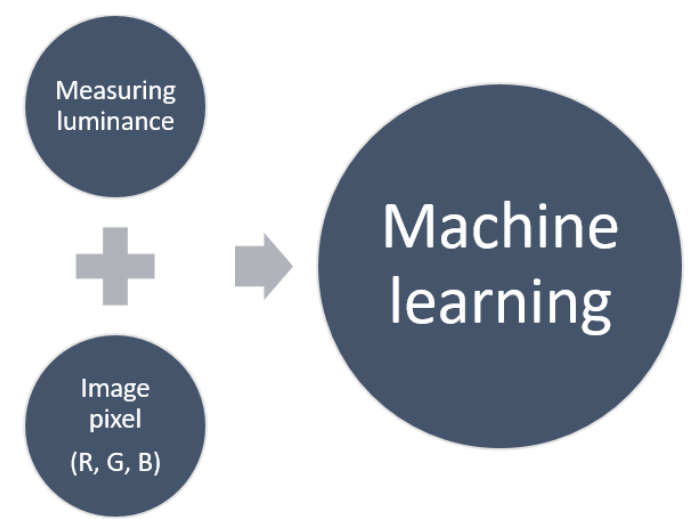

Figure 2. The working principle of the system

The system has three parts: measuring luminance, taking images and applying machine learning techniques.

\section{A. 1. Luminance Measurement}

In the project, a Konica Minolta LS-160 luminance meter was used for luminance measurements of the basketball court. As is indicated by FIBA for luminance measurements, reference points were identified on the basketball field. Grids should be formed above 1.5 meters of the playfield for vertical lighting measurements and on the floor for horizontal lighting measurements. In the present project, a grid of 2 meters by 2 meters were applied on the floor for horizontal lighting measurements in the basketball court. Grids designed for the basketball court can be seen in Figure 3.

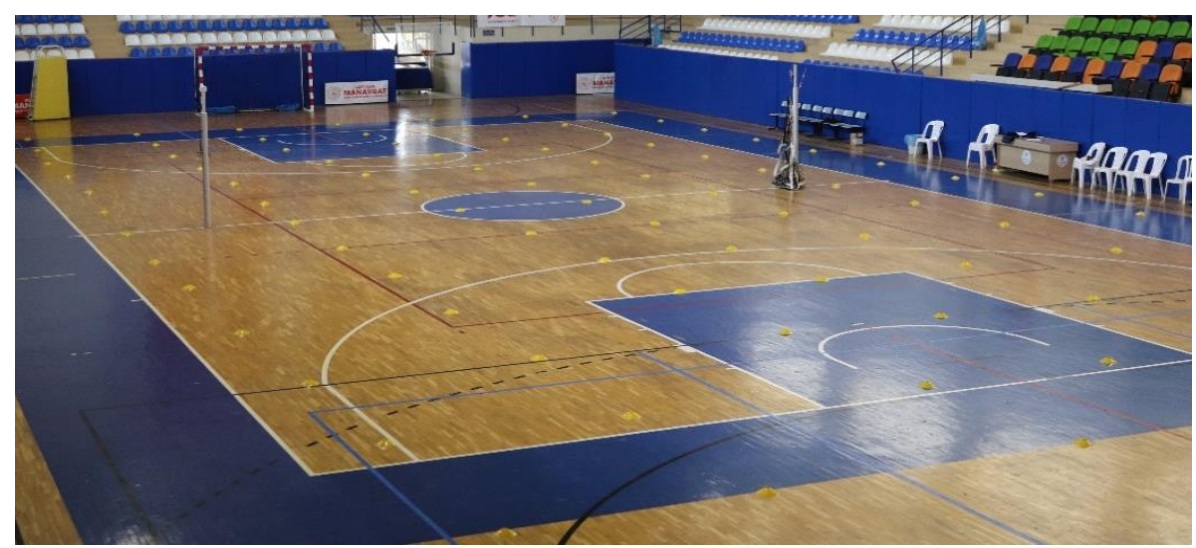

Figure 3. Grid the basketball hall 
The principle of luminance measurement using a luminance meter is shown in Figure 4. Luminance measurements were performed from the angular size of the camera and from the equivalent angle.

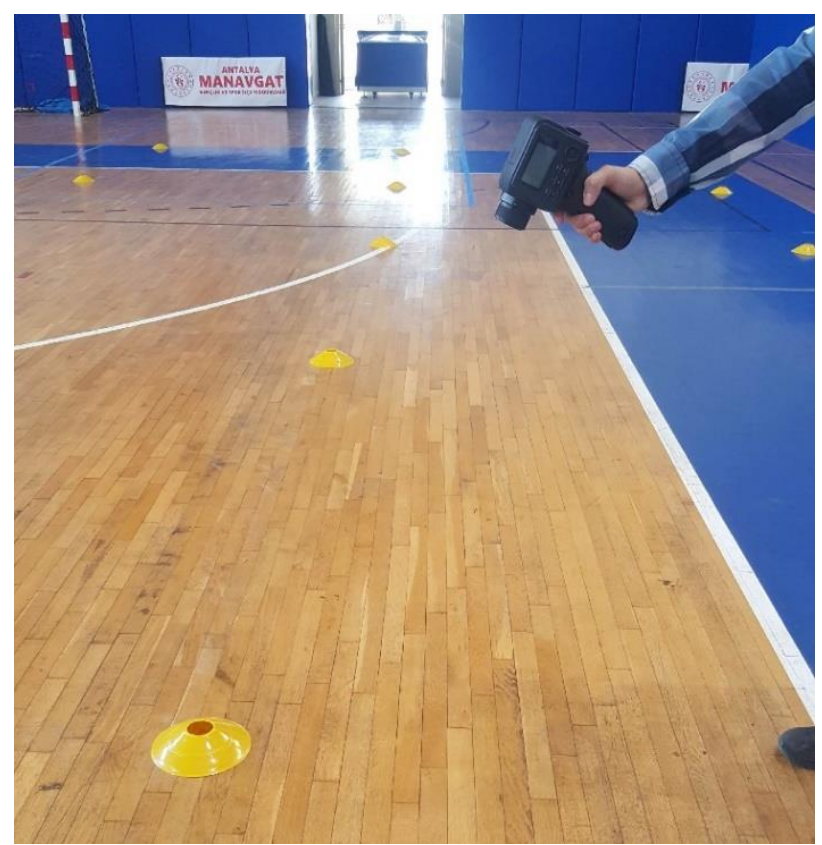

Figure 4. Luminance measurement

\section{A. 2. Image Acquisition System}

A high-definition image of the basketball court was taken in order to measure and analyse photometric values on this image. The most suitable viewing angle was found by taking images from different angles. An adjustable tripod system was installed for a standardized collection mechanism. This measuring mechanism has the capacity to take images from a height of 1.5 meters. Canon Eos 200D and $18-55 \mathrm{~mm}$ lens were used in order to capture images. Figure 5 demonstrates the image acquisition system used in the basketball court.

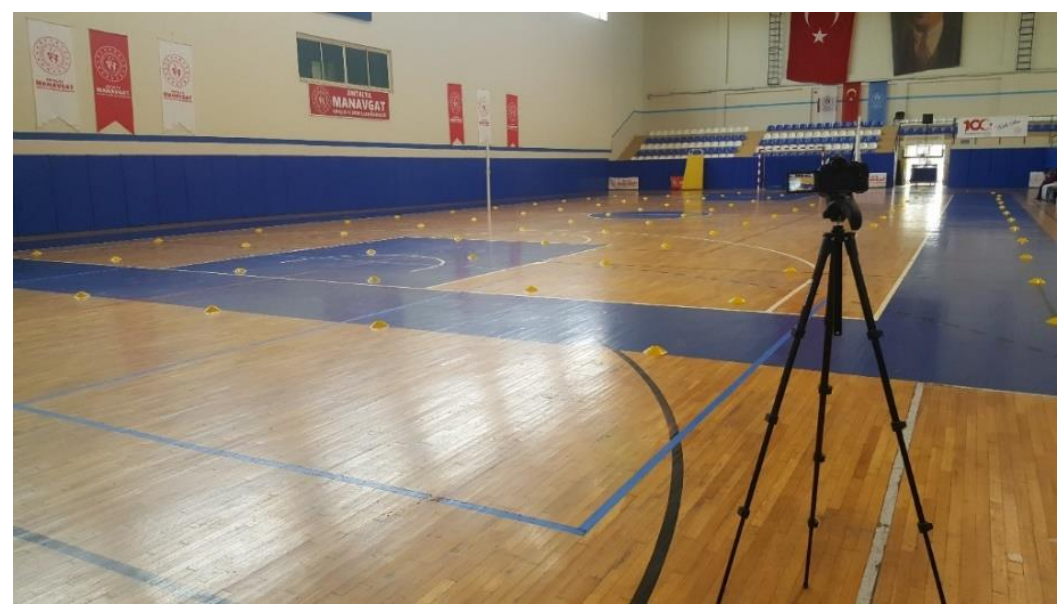

Figure 5. Image acquisition system 
Images taken by the camera are transferred to a digital image processing program (Adobe Photoshop CS). Mean R, G, B values on the image were found in the fields of these reference points on $25 \times 25$ pixel size.

\section{B. Machine Learning Techniques}

In study, Probabilistic Neural Network (PNN) and Support Vector Machine (SVM) were used as regression methods. Data training was conducted, and performance rates of these methods were found using test data.

\section{B. 1. Probabilistic Neural Networks (PNNs)}

Probabilistic neural networks (PNNs) offer an alternative to traditional backpropagation neural networks in classification problems without needing forward-backward computation related to ordinary neural networks [17]. In addition, they can function in smaller training data. It is a technique which replaces the sigmoid activation function often used in neural networks with an exponential function and which can measure within non-linear decision boundaries using Bayes' theorem [18].

The PNN algorithm [19] can be described as a group of neurons that combines different pairs in each layer in order to form new neurons in the next layer through a quadratic polynomial [20]. According to Bayes' theorem, if the equation of a given $\mathrm{x}$ vector (equation 4) is correct, it belongs to the first class and, if not, to the second class $[18,21]$.

$\frac{\mathrm{F}_{1}}{\mathrm{~F}_{2}}>\frac{\mathrm{L}_{1} \mathrm{P}_{1}}{\mathrm{~L}_{2} \mathrm{P}_{2}}$

In this equation, $F_{i}[11]$ is the probability of $x$ in the first class, $P_{i}$ is the probability of finding a first class, and $\mathrm{L}_{\mathrm{i}}$ is a cost coefficient indicating the significance level of the first class. Probability density functions are calculated with the formula in Equation 7 [21]:

$f(x)=\frac{1}{(2 \pi)^{m / 2} \sigma^{m} n} \sum_{i=1}^{n}\left[-\frac{\left(x-x_{i}\right)^{T}\left(x-x_{i}\right)}{2 \sigma^{2}}\right]$

In this equation, $\sigma$ is a parameter indicating the width of radial functions and called propagation coefficient or gap. Since the PNN has more computational complexity compared to other networks, it functions more slowly.

\section{B. 2. Support Vector Machine (SVM)}

Support Vector Machines (SVM) are machine learning algorithms based on convex optimization that works according to the principle of structural risk minimization [22]. In this method, the data are mapped to a higher dimensional input space and an optimum separation hyperplane in this area [23]. SVM is a widely used machine learning used for both regression and pattern recognition. Let $\mathrm{x} \in \mathrm{RN}$ and $\mathrm{y} \in \mathrm{R}$, where $\mathrm{RN}$ represents input space. By some nonlinear mapping $\Phi, \mathrm{x}$ is mapped into a feature space in which a linear estimate function is defined [24, 25]: 
$\mathrm{y}=\mathrm{f}(\mathrm{x}, \mathrm{w})=\mathrm{w} \Phi(\mathrm{x})+\mathrm{b}$

where w weight vector, $\mathrm{b}$ denotes the bias.

\section{EXPERIMENTAL WORKS}

PNN and SVM methods, one of the machine learning techniques, were used to learn the luminance on the surface of the indoor basketball hall. Application of these two methods has been done in KNIME program. The KNIME workflow system is an open source software that can be easily expanded with new tool integrations, has a powerful data system and allows workflow creators to document by providing a platform to solve these problems[26]. In KNIME, the user can model workflows that consist of nodes that process data and are transferred via connections between those nodes. It has a powerful and intuitive user interface, provides easy integration of new modules or nodes, and enables interactive search of analysis results or trained models [27]. KNIME is currently widely used in various research fields, for example, cheminformatics, image processing, artificial intelligence or classical data analysis[28, 29].

There are 91 reference points in the study. Training and test data in different ratios $(50 \%-50 \%$; 60$40 \% ; 80-20 \%$; $90 \%-10 \%$ ) have been tried in the system and the most successful results have been obtained in the ratio of $70 \%-30 \%$. Therefore, $70 \%$ of this data was used for training and $30 \%$ was used for testing. In other words, 64 of the data were used as training sets and 27 of them as test sets. The cluster selection of the data for testing and training was made randomly. The raw data were made ready for training and testing using the normalization method. Using normalization in artificial intelligence improves both performance and accuracy. One of the normalization techniques, Max-Min method was used; data were normalized from 0 to 1 . In equation 7 , the min-max normalization formula is given.

$\mathrm{x}^{\prime}=\frac{\mathrm{x}_{\mathrm{i}}-\mathrm{x}_{\min }}{\mathrm{x}_{\max }-\mathrm{x}_{\min }}$

PNN model used in this study consists of 3 layers: The Input layer, Radial Basis Layer and the Competitive Layer. In the Radial Base Layer, the vector distances between the input vector and the weight vector made from the line of each weight matrix are calculated. Here, the vector distance is defined as the dot product between two vectors. The Competitive Layer finds the shortest distance between them and thus finds the closest training model to the entry order according to their distance. As a result of the numerous of tests carried out, the parameters were used as mean value method mean, theta minus 0,5 ; theta plus is set to 0.9 .

Non-linear method was used as SVR types. Different combinations were tested for C and $\varepsilon$, which have SVR parameters, and finally we decided to perform well with $\varepsilon 0.01$ and C 1000 and decided to use it. Radial basis function (RBF) was preferred as the core function as the most successful result as a result of the tests. In equation 8 , the min-max normalization formula is given.

$K\left(x_{i}, x_{j}\right)=\exp \left(-\gamma \mid\left(\left.x_{i} \cdot x_{j}\right|^{2}\right) 1\right.$ 
Table 1. The results of the artificial intelligence techniques

\begin{tabular}{lcc}
\hline & PNN & SVM \\
\hline MSE & 0,0408 & 0,0578 \\
\hline RMSE & 0,2021 & 0,2401 \\
\hline Correlation coefficient (r) & 0,47008 & 0,36477 \\
\hline Accuracy Rate (\%) & $\% 65,71$ & $\% 74,51$ \\
\hline
\end{tabular}

A comparative graphical representation of the results of the test data in Table 1 is given in Figure 6.

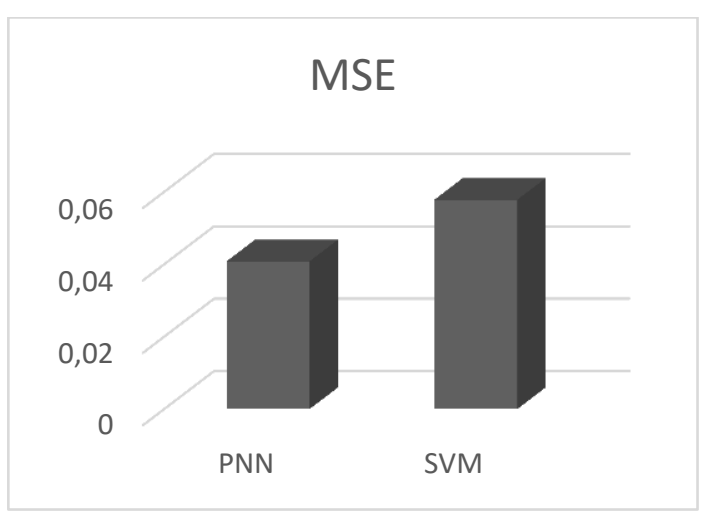

[1]

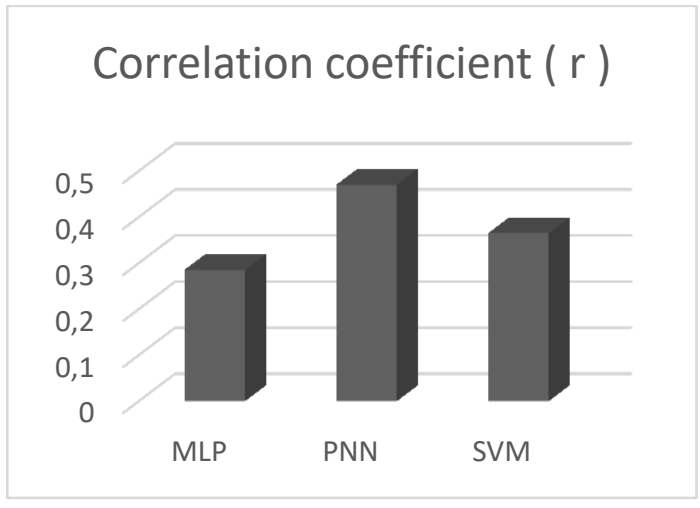

[1]

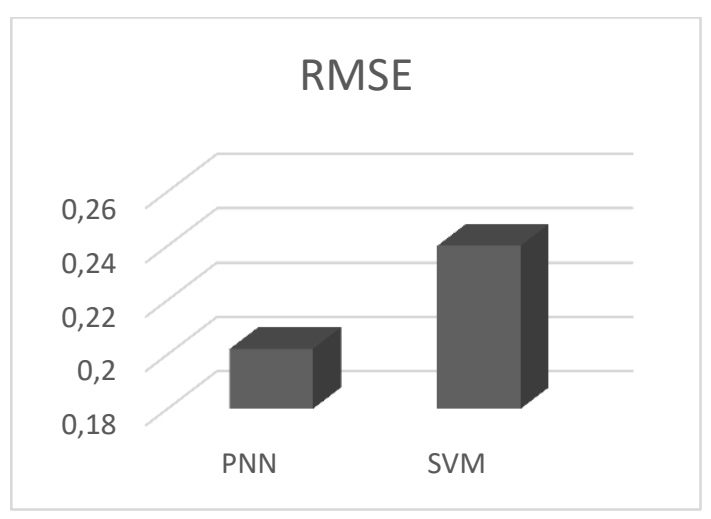

[10]

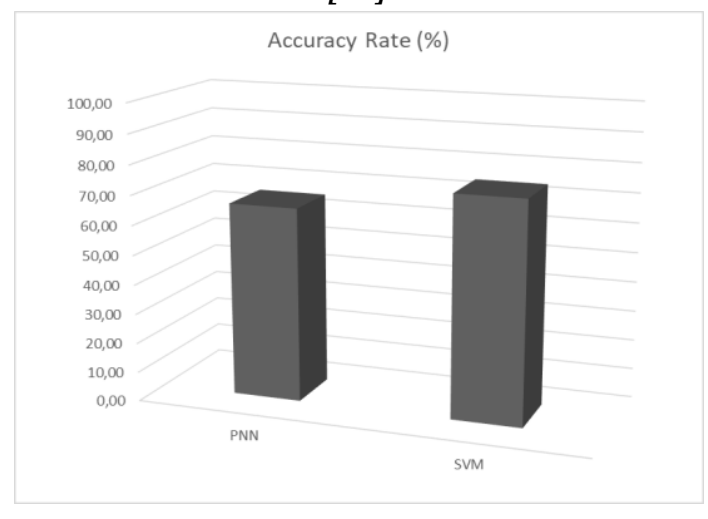

[1]

Figure 6. Results of test data a. MSE b. RMSE c. Correlation coefficient [1] d. Accuracy rate

The MSE (Figure 6.a) and RMSE (Figure 6.b), which enable us to measure error values, close to zero indicate that the results are successful. According to these two values, the best methods are PNN and SVM, respectively.

Correlation coefficient [1] (Figure 6.c) equal to 1 indicates an excellent positive linear relationship. If the $\mathrm{R}$ value is equal to zero, it indicates that there is no linear relationship. According to the results, the best correlation is in PNN and SVM, respectively.

According to the accuracy rate (Figure 6.d), the best method is SVM and PNN, respectively. 


\section{CONCLUSION}

In order to provide a healthy vision in sports competitions and to maintain athletes' health, lighting measurements should be conducted periodically in indoor sports halls. Due to the point measurement of luminance meters and the excess number of measuring points indicated in the standards, it takes longer to perform measurements.

In this study, luminance measurements in sports halls as a new method were performed using machine learning methods with a high success rate. Thanks to this system, luminance measurements of every single point in indoor sports halls could be performed in a shorter period of time. As indicated in the working standards, 91 measuring points were identified, and these were randomly categorized as training $(70 \%)$ and test $(30 \%)$ data. The results of the measurements conducted with two different machine learning techniques demonstrated that SVM had the higher success rate.

Luminance meters are used in order to measure the amount of light reflected from the surface. Therefore, reflection coefficient of the surface in the sports hall affect measurements (surface structure, surface colour and surface deformation coefficient). Therefore, measurements in different halls are required in order to form a unique data set specific for the hall.

Since there are many factors affecting the measurement results, the success rate has been relatively low compared to other studies using machine learning methods. In the future, tests are planned again with this method and other methods in different sports halls (preferably sports halls with new ground and lighting not worn). In addition, data set indicated in the standards (the number of reference measuring points) could be increased in order to reduce the error rate and to increase the success rate.

ACKNOWLEDGEMENTS: This work was supported by The Scientific Research Projects Coordination Unit of Akdeniz University. Project Number: 3899

\section{REFERENCES}

[1] K. W. Houser, M. Royer, and R. G. Mistrick, "Light loss factors for sports lighting,", The Journal of the Illuminating Engineering Society, vol. 6, no. 3, pp. 183-201, 2010.

[2] K. W. Houser, M. Wei, and M. P. Royer, "Illuminance uniformity of outdoor sports lighting,", The Journal of the Illuminating Engineering Society, vol. 7, no. 4, pp. 221-235, 2011.

[3] C. H. Hsu, "The Effects of Lighting Quality on Visual Perception at Sports Events: A Managerial Perspective," International Journal of Management, vol. 27, no. 3, pp. 693-703, 2010.

[4] L. Tao, Y. Mengming, and Y. Meng, "Study of glare evaluation system for indoor sports lighting,", Electrical Technology of Intelligent Buildings, vol. 2, no.1, pp. 19-23, 2008.

[5] T. Goodman, "Measurement and specification of lighting: A look at the future," Lighting Research \& Technology, vol. 41, no. 3, pp. 229-243, 2009. 
[6] H. Zhou, F. Pirinccioglu, and P. Hsu, "A new roadway lighting measurement system," Transportation Research Part C: Emerging Technologies, vol. 17, no. 3, pp. 274-284, 2009.

[7] R. A. Zimmer, "Mobile illumination evaluation system," Transportation Research Record, vol. 1172, pp. 68-73, 1988.

[8] A. Zatari, G. Dodds, K. McMenemy, and R. Robinson, "Glare, luminance, and illuminance measurements of road lighting using vehicle mounted CCD cameras," The Journal of the Illuminating Engineering Society, vol. 1, no. 2, pp. 85-106, 2005.

[9] J. He, Z. Zhu, F. Wang, and J. Li, "Illumination Control of Intelligent Street Lamps Based on Fuzzy Decision,", International Conference on Intelligent Transportation, Big Data \& Smart City (ICITBS), Changsha, China, 513-516, (2019).

[10] T. Muhammad, Y. Guo, Y. Wu, W. Yao, and A. Zeeshan, "CCD Camera-Based Ball Balancer System with Fuzzy PD Control in Varying Light Conditions,", IEEE 16th International Conference on Networking, Sensing and Control (ICNSC), Banff, Canada, 305-310, (2019).

[11] P. Mohandas, J. S. A. Dhanaraj, and X.-Z. Gao, "Artificial Neural Network based Smart and Energy Efficient Street Lighting System: A Case Study for Residential area in Hosur," Sustainable Cities and Society, vol. 48, no. 101499, pp. 1-13, 2019.

[12] M. Kayakuş and I. Üncü, "Research note: the measurement of road lighting with developed artificial intelligence software," Lighting Research \& Technology, vol. 51, no. 6, pp. 969-977, 2019.

[13] M. Şahin, Y. Oğuz, and F. Büyüktümtürk, "ANN-based estimation of time-dependent energy loss in lighting systems," Energy and Buildings, vol. 116, pp. 455-467, 2016.

[14] T. Kazanasmaz, M. Günaydin, and S. Binol, "Artificial neural networks to predict daylight illuminance in office buildings," Building and Environment, vol. 44, no. 8, pp. 1751-1757, 2009.

[15] R. W. da Fonseca, E. L. Didoné, and F. O. R. Pereira, "Using artificial neural networks to predict the impact of daylighting on building final electric energy requirements," Energy and Buildings, vol. 61, pp. 31-38, 2013.

[16] de Basketball, Fédération Internationale. "Official Basketball Rules." (2000).

[17] B. Mohebali, A. Tahmassebi, A. Meyer-Baese, and A. H. Gandomi, "Probabilistic neural networks: a brief overview of theory, implementation, and application," in Handbook of Probabilistic Models: Elsevier, 2020, pp. 347-367.

[18] D. F. Specht, "Probabilistic neural networks," Neural networks, vol. 3, no. 1, pp. 109-118, 1990.

[19] N. Nariman-Zadeh, A. Darvizeh, M. Darvizeh, and H. Gharababaei, "Modelling of explosive cutting process of plates using GMDH-type neural network and singular value decomposition," Journal of Materials Processing Technology, vol. 128, no. 1-3, pp. 80-87, 2002. 
[20] M.-W. Cho, G.-H. Kim, T.-I. Seo, Y.-C. Hong, and H. H. Cheng, "Integrated machining error compensation method using OMM data and modified PNN algorithm," International Journal of Machine Tools and Manufacture, vol. 46, no. 12-13, pp. 1417-1427, 2006.

[21] G. Kumaşoğlu and B. Bolat, "Yapay sinir ağlarıyla müzikal tür tanıma,", Elektrik-Elektronik Bilgisayar Sempozyumu (FEEB), Elazı ğ, Turkey, 5-7, (2011).

[22] S. Ayhan and Ş. Erdoğmuş, "Destek vektör makineleriyle sınıflandırma problemlerinin çözümü için çekirdek fonksiyonu seçimi," Eskişehir Osmangazi Üniversitesi İktisadi ve İdari Bilimler Dergisi, vol. 9, no. 1, pp. 175-201, 2014.

[23] J. A. Suykens and J. Vandewalle, "Least squares support vector machine classifiers," Neural processing letters, vol. 9, no. 3, pp. 293-300, 1999.

[24] L. Zhang, W. Zhou, and L. Jiao, "Wavelet support vector machine," IEEE Transactions on Systems, Man, and Cybernetics, Part B (Cybernetics), vol. 34, no. 1, pp. 34-39, 2004.

[25] S. K. Shevade, S. S. Keerthi, C. Bhattacharyya, and K. R. K. Murthy, "Improvements to the SMO algorithm for SVM regression," IEEE Transactions on Neural Networks, vol. 11, no. 5, pp. 1188-1193, 2000.

[26] A. Fillbrunn, C. Dietz, J. Pfeuffer, R. Rahn, G. A. Landrum, and M. R. Berthold, "KNIME for reproducible cross-domain analysis of life science data," Journal of Biotechnology, vol. 261, pp. 149156, 2017.

[27] Berthold, M. R., Cebron, N., Dill, F., Gabriel, T. R., Kötter, T., Meinl, T., Ohl, P., Thiel, K., Wiswedel, B., "KNIME-the Konstanz Information Miner: Version 2.0 and Beyond," AcM SIGKDD Explorations Newsletter, vol. 11, no. 1, pp. 26-31, 2009.

[28] C. Dietz and M. R. Berthold, "KNIME for open-source bioimage analysis: a tutorial,", Focus on Bio-Image Informatics: Springer, 2016.

[29] S. Yu, D. Zhao, W. Chen, and H. Hou, "Oil-immersed power transformer internal fault diagnosis research based on probabilistic neural network," Procedia Computer Science, vol. 83, pp. 1327-1331, 2016. 